\title{
Centers for Disease Control and Prevention
}

National Cancer Institute

\section{Source}

National Cancer Institute. Centers for Disease Control and Prevention. NCI Thesaurus.

Code C16408.

An agency of the US Public Health Service that serves as the national focus for developing and applying disease prevention and control, environmental health and health promotion and health education activities designed to improve the health of the people of the United States. The CDC is responsible for controlling the induction and spread of infectious diseases, and provides consultation and assistance to other nations and international agencies to assist in improving their disease prevention and control, environmental health, and health promotion activities. 